\title{
Study of Cooling Gases for Windage Loss Reduction
}

\author{
Member Ajisman \\ (Tokyo Institute of Technology) \\ Non-member Kazuhiro Yamagata \\ (Tokyo Institute of Technology) \\ Member Jun Kobuchi \\ (Tokyo Institute of Technology) \\ Member Ryuichi Shimada \\ (Tokyo Institute of Technology)
}

\begin{abstract}
The windage loss gives some contribution to the total losses of high-speed rotary machine such as motor/ generator with flywheel or turbines. In order to overcome this problem, the rotor can be operated in a low pressure/vacuum chamber. However, this method finds difficulties in removing heat from the rotor, to seal and to design suspension system. In addition, its breakdown voltage is very low. This paper presents experimental results of windage loss reduction using helium and air mixture that also has the property of cooling gases. The results show significant windage loss reduction for Helium (50\%) and air (50\%) mixture with a breakdown voltage of about $88 \%$ that of the air. The breakdown voltage and thermal property of the gases have also been measured.
\end{abstract}

Key words : Breakdown voitage, Windage loss, Gas mixture, Flywheel energy storage

\section{Introduction}

The windage loss gives some contribution to the total losses of machine using high speed rotaing parts. To reduce the windage loss, the rotor can be put in a low pressure/vacuum chamber. However, the vacuum chamber has the following problems: the removal of heat to the outside, a special bearing system, sealing and its low breakdown voltage. For an electric rotary machine such as motor/generator flywheel, the low breakdown voltage of the gases creates another problem, for example it leads to breakdown amongst the slip rings. In addition, a wise judgment should be made between the energy needed to support the vacuum system and the energy loss itself.

Hydrogen is often used as a gaseous cooling medium in large electrical machines due to its good thermal conductivity, but there are some disadvantages such as low breakdown voltage, and explosion when mixed with oxygen. In addition, pemeation rate of hydrogen is greater than that of other gases so that the speed of fatigue/crack caused by hydrogen is also faster than that of other gases such as helium ${ }^{(1)}$. It can cause much friction loss in the bearing system and lead to the failure of the flywheel system, which could create serious problems. The gases used in high voltage environment should have characteristics such as high breakdown voltage, good thermal conductivity, low density, noninflammability and so on. Among natural gases, air/ nitrogen and helium mixtures are good candidates. $\mathrm{He}$ and $\mathrm{SF}_{6}(15 \%)$ can also reduce windage loss significantly with breakdown voltage better than that of $\operatorname{air}^{(2)}$, however $\mathrm{SF}_{6}$ is relatively expensive.

The windage loss is relatively large, about $15 \%$ of the total losses for a conventional generator with rated 300 $\mathrm{MVA}^{(3)}$. If this loss could be reduced, it would increase the overall efficiency of the machine. For example the flywheel motor/generator of JT-60, the fusion device of the Japan Atomic Energy Research Institute, has an energy storage capacity of $8 \mathrm{GJ}$. The windage loss contribution of this system is $2,640 \mathrm{~kW}(50 \%)$ from $5,240 \mathrm{~kW}$ of the total losses as shown in Table $l^{(4)}$. If this power loss were converted to energy used over customary 40-years of lifetime of the machine, it would

Table 1. Rotational loss of JT-60 Toroidal generator (rated speed $600 \mathrm{rpm}$ ).

\begin{tabular}{l|c}
\hline thrust bearing friction loss & $700 \mathrm{~kW}$ \\
\hline thrust bearing shake up loss & $900 \mathrm{~kW}$ \\
\hline guide bearing loss & $700 \mathrm{~kW}$ \\
\hline self pump loss & $300 \mathrm{~kW}$ \\
\hline generator windage loss & $1,800 \mathrm{~kW}$ \\
\hline flywheel windage loss & $840 \mathrm{~kW}$ \\
\hline Total & $5,240 \mathrm{~kW}$ \\
\hline
\end{tabular}


save significant amount of operating cost.

This paper presents the experimental results of a mixed gas that can be used to reduce windage loss with characteristics low density, high breakdown voltage and better heat transfer.

\section{Windage Loss of Rotating Disk}

For a rotating machine, the windage and friction loss contribute large enough to the total loss. In order to find out the windage loss a spindle bearing has been used to support a ring-shaped flywheel connected to a hub using an aluminum disk. The spindle bearing has very low mechanical friction loss. The basic configuration and picture of the flywheel system are shown in Figs 1 and 2, respectively. Because of very low friction loss, the total losses of the flywheel can be assumed as windage loss only.

The flywheel system has been operated in a chamber so that the surrounding of the flywheel with respect to gases, or vacuum with medium pressures about 10 torr can be easily detemined. The flywheel system is connected to the outside by means of a mechanical clutch. Table 2 shows the main dimension of the flywheel.

The flywheel system stores energy in the form of kinetic type. Eq. (1) and (2) show stored energy and charging or discharging power, respectively.

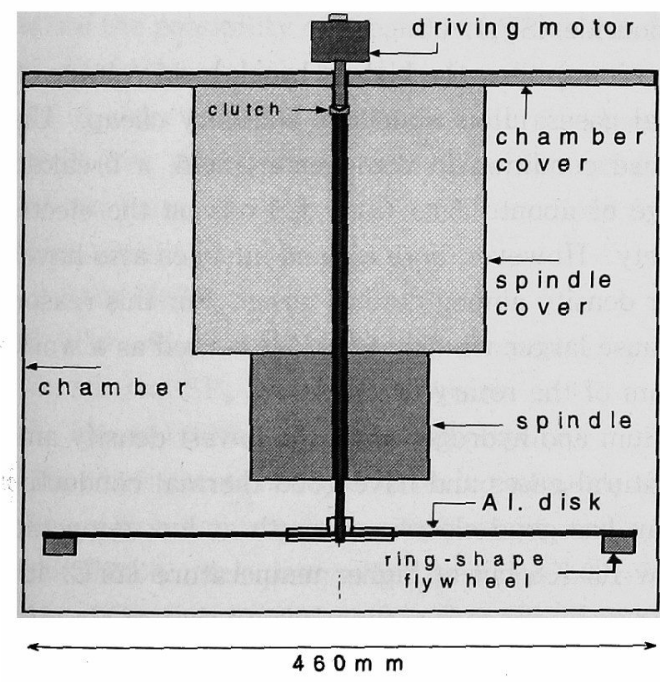

Fig. 1. Basic configuration of spindle flywheel.

Table 1 Parameters of spindle flywheel.

\begin{tabular}{l|c}
\hline In-side diameter $(\mathrm{mm})$ & 360 \\
\hline Out-side diameter $(\mathrm{mm})$ & 420 \\
\hline Thickness $(\mathrm{mm})$ & 40 \\
\hline Material & iron \\
\hline Moment of inertia $\left(\mathrm{kg}-\mathrm{m}^{2}\right)$ & 0.524 \\
\hline
\end{tabular}

$$
\begin{aligned}
& E=\frac{1}{2} I \omega^{2} \\
& P=\frac{\Delta E}{\Delta t}=\frac{I\left(\omega_{2}^{2}-\omega_{1}^{2}\right)}{2\left(t_{2}-t_{1}\right)}
\end{aligned}
$$

Here $E, P$ and $I$ are energy storage $(\mathrm{J})$, power (W), and moment of inertia $\left(\mathrm{kg}-\mathrm{m}^{2}\right)$ of the flywheel, respectively. The power loss of the flywheel can be determined by the energy change in an interval of time $(\Delta t)$ as described by Eqs (1) and (2), and shown Fig. 3.

Experiment procedures :

- The flywheel is speed up to about 3,000 rpm by using a $600 \mathrm{~W}$ DC motor connected by the clutch.

- The motor-clutch system is removed and a seal is used to cover the clutch hole.

- The tested gas is injected into the chamber with a total pressure of about 760 Torr.

- The coasting speed of the flywheel is counted by using an optical sensor and a digital signal processing interfaced to a computer.

The time is needed to remove the motor-clutch system, to put seal on the hole of the chamber and to insert tested gas into the chamber. Because of this time

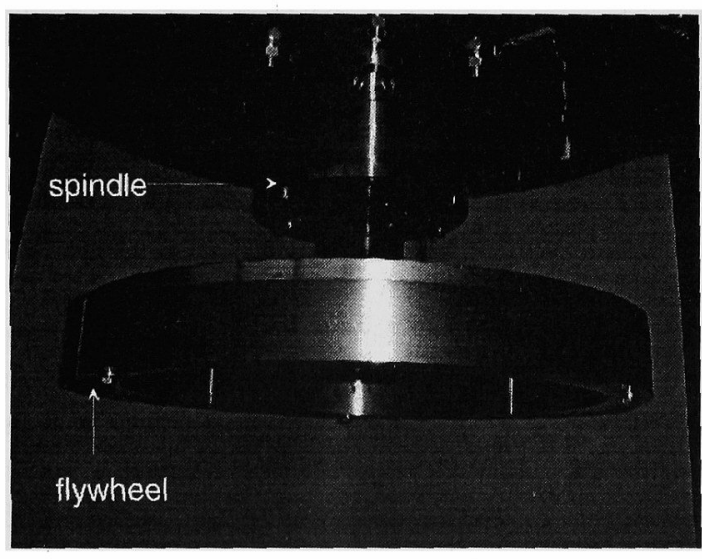

Fig. 2. Picture of the flywheel supported by a spindle bearing.

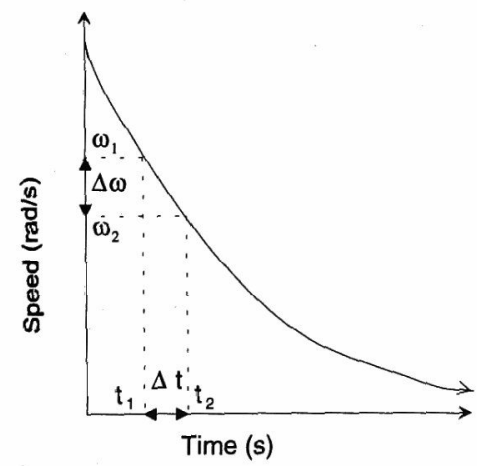

Fig. 3. Rotating speed vs. time. 


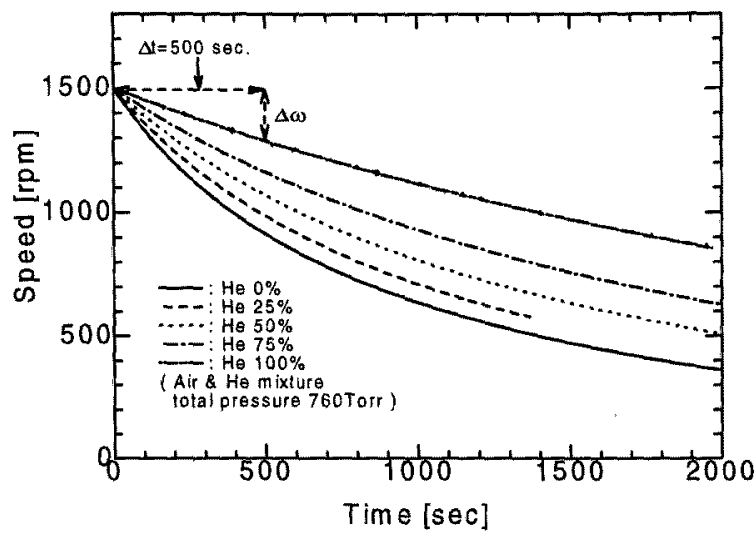

Fig. 4. Rotating speed vs. time.

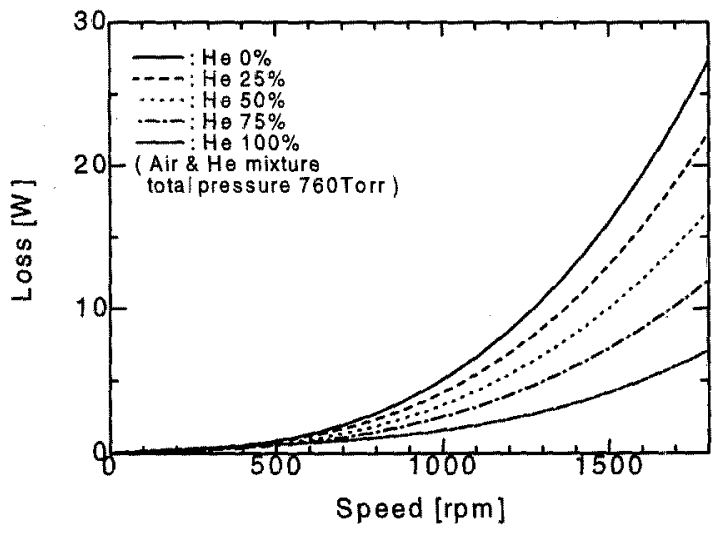

Fig. 5. Loss vs, rotating speed.

interval, the speed was reduced from about $3,000 \mathrm{rpm}$ to $2,000 \mathrm{rpm}$.

The experiment is carried out by running the flywheel system inside the chamber with helium and air mixture as the surrounding medium. The gas with lowest density will take more time to reach the lower speed as shown in Fig. 4. For instance, the negative acceleration $(\Delta \omega / \Delta t)$ of the flywheel for pure helium is only $69 \%$ that of air for an interval of 500 seconds, and about $80 \%$ for He $(50 \%)$ mixture for the same period. For a longer time, speed slows down so that there is no significant windage loss.

With time, the speed of the flywheel reduces and the stored energy is also reduced, as the kinetic energy is proportional to the square of angular speed. The power loss is determined by dividing the amount of energy for a certain period by its interval time as defined by Eq. (2). Figure 5 shows the rotation loss of the flywheel. The total losses of the flywheel using $\mathrm{He}(50 \%)$ and air $(50 \%)$ mixture is about $42 \%$ to that of air.

The windage loss is dependent on the gas density and angular speed as shows in Fig. 6 which is derived from

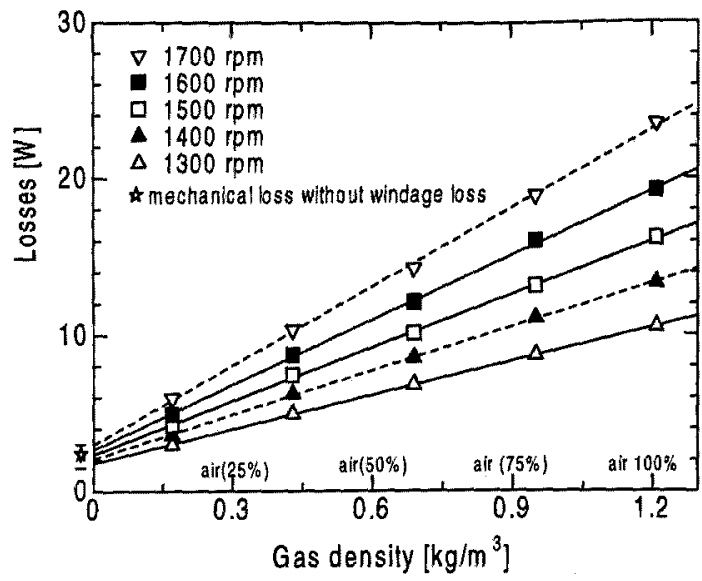

Fig. 6. Losses vs. gas density.

Fig. 5. By investigating Fig. 6, that is for certain loss and speed, the density of the gas mixture could be tailored for this application. In addition, the mechanical loss could also be determined using this figure. For example, at zero density or vacuum there is no windage loss, but there is friction. At a speed between, $1,700 \mathrm{rpm}$ and $1,300 \mathrm{rpm}$ friction loss is around $2 \mathrm{~W}$.

\section{Some Characteristics of Gases}

There are important gases used as insulating or cooling agent in highvoltage technology applications such as air/nitrogen, hydrogen, helium and sulphurhexaflouride $\left(\mathrm{SF}_{6}\right)$

Air/nitrogen has the highest breakdown voltage of all natural gases. It is abundant and very cheap. Under standard condition in homogenous field, a breakdown voltage of about $3.5 \mathrm{kV} / \mathrm{mm}$ depends on the electrode geomety. However, both air and nitrogen also have the higher density among natural gases. For this reason, it can cause larger windage loss if it is used as a working medium of the rotary machine.

Helium and hydrogen have the lowest density among the natural gases and have good thermal conductivity. Helium has good electric strength at low temperature (below $100 \mathrm{~K}$ ), but at higher temperature $\left(20^{\circ} \mathrm{C}\right)$ it has breakdown voltage less than $30 \%$ to that of air. If this gas is used as the working medium for a rotary machine, the flashover will occur at the slip ring of the motor/ generator.

Hydrogen is often used as gaseous cooling medium in large electrical machines due to its good thermal con ductivity. This gas has some disadvantages, among which are: Its electrical breakdown voltage is about $50 \%$ to that of air. There is a certain amount of hazard such as explosion caused by the possibility of air 
(oxygen) mixing with hydrogen in the machine or in pockets outside ${ }^{(5)}$. The permeation rate of hydrogen is greater than that of other gases. These characteristics can lead to fatigue on the flywheel. If this condition is unchecked, it could create serious problems when a fault occurs on a large electrical machine.

Sulfur-hexafluoride $\left(\mathrm{SF}_{6}\right)$ not only has the highest breakdown voltage compared to that of the other gases $^{(6)}$, but its density is also the highest. If it is used as a working medium for a rotary machine, it will result in increased windage loss.

It is well known that the presence of small amount of electronegative gases, which have electron affinity, tends to raise the breakdown voltage of the $\operatorname{gases}^{(6)} . \mathrm{SF}_{6}$, oxygen, and hologen compound are gases of this type. Other gases such as noble gases ( $\mathrm{He}, \mathrm{Ne}, \mathrm{Ar}$, etc.) have little affinity to form negative ions. If there is a mixture of $\mathrm{He}$ and $\mathrm{SF}_{6}$, or $\mathrm{He}$ and air, the breakdown voltage could be increased and relatively low-density gases can be produced.

\subsection{Breakdown voltage of tested gases}

For high voltage devices, the voltage breakdown phenomenon is an important aspect. For example, among the slip rings of generator/motor often occur sparkover, which might affect the perfomance of the motor/generator. As a result, the working medium of the rotary part of the motor/generator should be able to withstand the possibility of breakdown. This means the gases should have high breakdown voltage and low density in order to avoid insulation failure and achieve relatively low the windage loss. For this study the breakdown voltage experiments have been done for the following gases:

(a) Air 100\%

(b) He and air mixture at any composition

(c) $\mathrm{He}$ and $\mathrm{SF}_{6}$ at any composition

(d) He and nitrogen at any composition

All the experiments have been conducted inside a steel chamber, which has a volume of about $70 \mathrm{l}$. The percentage of each gas is determined by its pressure in the chamber. The total pressure in the chamber is set at 760 Torr, and the humidity at room temperature is about $30 \%$.

Each gas is subjected to breakdown voltage using air gap, surface and conventional terminal connector. These shapes are often found as parts of electric machines such as slip rings, commutators and terminals. The gap between electrodes is fixed as in actual electric machines. The air gap electrode is made of spherical stainless steel with $30 \mathrm{~mm}$ in diameter. The surface electrode consists of two pieces of copper plate put on a renforced fiber plastic. Both spherical and surface electrodes have an air gap length of $1 \mathrm{~mm}$. The terminal connector is a commonly used terminal connector with a rated voltage of $600 \mathrm{~V}$.

Figures 7 and 8 show the experiment layout and the picture for breakdown voltage, respectively. The slide transformer is used to control the primary side of a high voltage transformer of $7 \mathrm{kV}$. The primary voltage is increased slowly until the secondary side reaches the breakdown voltage of the gases.

For the terminal connector, the applied voltage is set about 3 times its rated value for one-minute duration. The breakdown occurs for pure helium, but for air and helium ( $25 \%$ or more) mixture the connector can withstand for 1 minute. It is the same for $\mathrm{He}$ and $\mathrm{SF}_{6}(1 \%)$ mixture.

For helium and nitrogen mixture, it is found that the breakdown voltage for surface electrode is much lower than that of air. For $\mathrm{SF}_{6}(5 \%)$ and helium mixture, the breakdown voltage is about $70 \%$ that of air.

For helium $(50 \%)$ and air (50\%) mixture, breakdown voltage is nearly equal to that of air as shown in Fig. 9 where the windage loss can be reduced to $42 \%$ to that of air. The increasing breakdown voltage of the helium

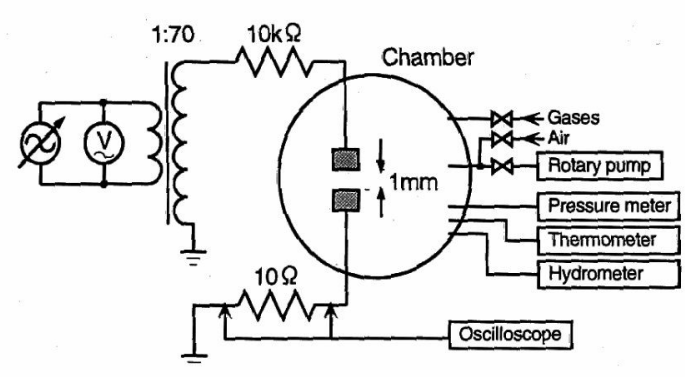

Fig. 7. Experiment layout for breakdown voltage test across the electrode.

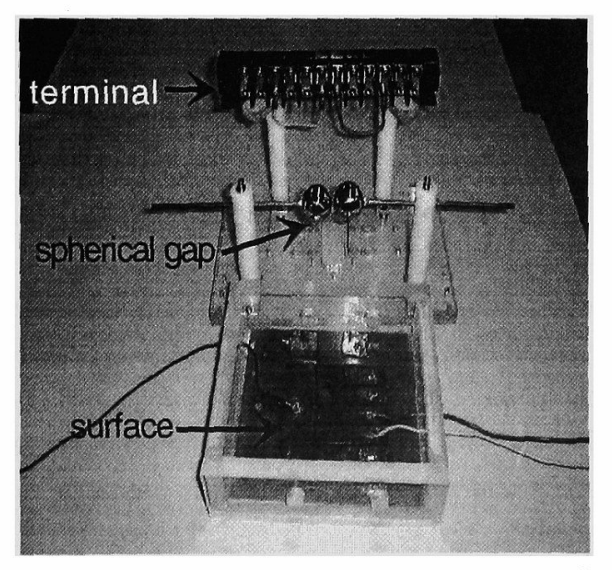

Fig. 8. Electrodes for breakdown test. 


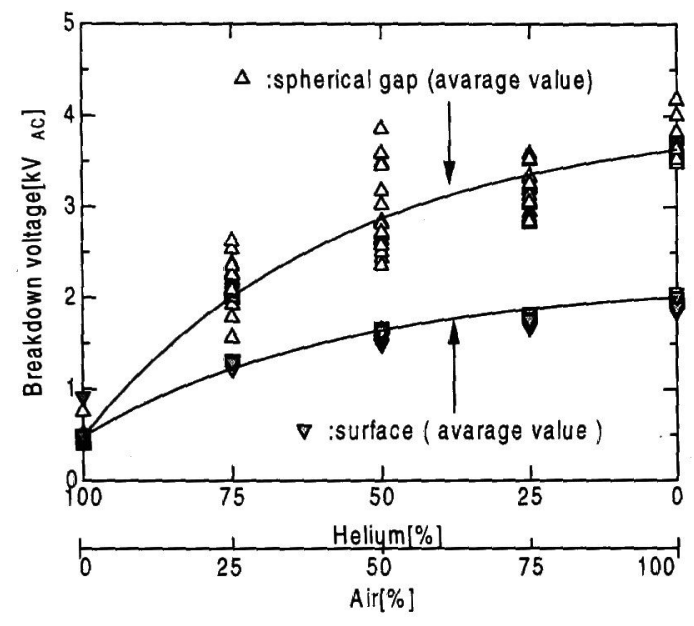

Fig. 9. Breakdown voltage of $\mathrm{He}$ and air mixture.

and air mixture comes from oxygen, an electronegative gas, which exists in air composition ${ }^{(6)(7)}$.

\section{2 Thermal property of the tested gases}

The working medium of a rotary machine should have good themal conductivity in addition to lower density, and higher breakdown voltage. The thermal property of the tested gases has been investigated quantitatively by using a diode that is mounted on a heat $\sin k$, and a themal sensor. The diode is connected to a 6-ampere DC current source, and its layout is shown in Fig. 10. The heat dissipated in the vicinity of $p-n$ junction flows to the case and then to the mixed gas through the heat sink. The thermal sensor put close to the diode is used as a back up to measure the temperature of the heat sink.

Because of the characteristics of semiconductor, the change in temperature causes a change in junction voltage or current, so that the change in temperature caused by cooling property of surrounding gases can be detected directly.

The relationship between temperature and the drop voltage at the $p^{-n}$ junction of the diode can be understood from the ideal diode equation ${ }^{(8)}$ :

$$
I=I_{0}\left\{\exp \left(\frac{q V}{k T}\right)-1\right\}
$$

Here $I$ and $I_{0}$ are the forward and the reverse saturation current, respectively.

For each gas, the current of 6 ampere was kept flowing until the junction voltage of diode reaches a constant value. The heat of the $p-n$ junction is transmitted to the heat sink via its case and then the temperature indicated by thermal sensor, which is put next to diode, was recorded.

The thermal property is searched only for helium and

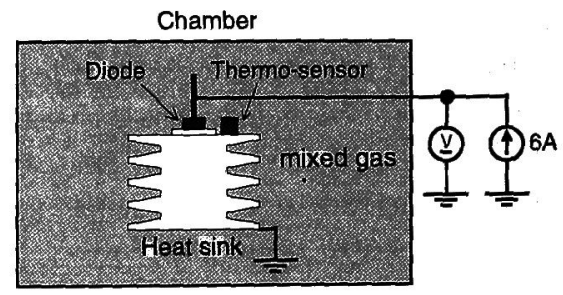

Fig. 10. Experiment layout for themal test.

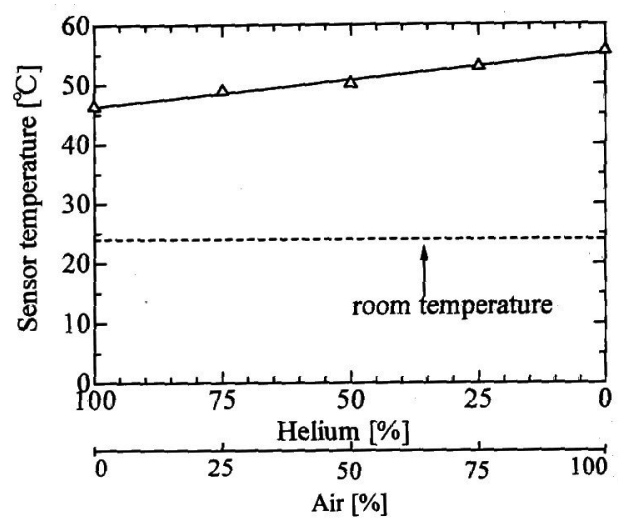

Fig. 11. The steady state temperature in tested gases.

air mixture with various percentages. From Fig. 11, it can be understood that helium $(50 \%)$ and air (50\%) mixture has a better heat transfer to the surrounding than air, because the thermal sensor indicates a lower temperature of the gases than that of air.

\section{Conclusion}

The Helium $50 \%$ and air $50 \%$ mixture gas has been used mainly for windage loss reduction. The windage loss reduction of the rotating disk that can be achieved is about $42 \%$ to that of air. Thermal property of this gas mixture is better than that of air and its breakdown voltage is nearly equal to that of air.

This gas could be applied either as working or cooling medium of electric machines such as motor/generator, flywheel energy storage, and turbine because of its lower density, good thermal property, and relatively high breakdown voltage. As a result, the operating cost could be reduced significantly due to lower windage and heat losses.

\section{Acknowledgement}

The authors gratefully acknowledge useful suggestions and helps from our colleagues of Shimada Laboratory, especially: Mr. Koizumi, Mr. Nakamura, and Mr. Oobayashi.

(Manuscript received April 23, 1999, revised Sept. 21, 1999) 


\section{References}

（1）島津登志成・槄 浩司:「電車線用フライホイール発電電動機」, 三菱電機技報, 63, No. 8 (平元)

(2) Ajisman, J. Kobuchi, K. Oobayashi \& R. Shimada: "Windage Loss Reduction of Flywheel/Generator System Using He and $\mathrm{SF}_{6}$ Gas Mixtures", $32^{\text {nd }}$ IECEC, vol. 4, International Conference, Honolulu, Hawaii (1997)

(3) R. D. Blaugher: "Low-calorie, High-energy Generator and motors", Spectrum IEEE (1997-7)

（4）捣田・谷本・大森・松川:「核融合電源用フライホイール電動発 電機の短周期ロードレベリング装置への適用」, 平元電気学会全 大, No. 1505

（5）大森, 他：「JT-60ライダル磁場コイル電源フライホイール付発 電機の運転効率」,昭 60 プラス゚マ・核融合学会全大

(6) I. D Cobin: "Some Electrical and Thermal Characteristics of Helium and Sulfur-hexafluoride Mixtures", AIEE (1955-7)

(7) N. Rao: High-Voltage Insulation Technology (1985) Friedr Vieweg \& Sohn verlagsgesellshhaff

(8) G.W. Newdeck: The PN Junction Diode, vol. 2 (1989) Addition-Wisley Publishing Co.

Ajisman (Member) He born in Padang. West Sumatra, In-

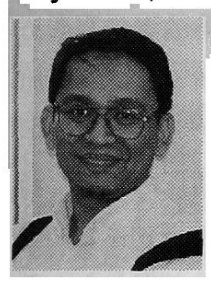
donesia in 1959 . He received his B. S. degree, from Indonesia University, Jakarta, in "1986, and his M. S. degree from Tokyo Institute of Technology, Tokyo, in 1992, both in Electrical Engineering. Now, he is currently a doctoral student at Tokyo Institute of Technology, Japan. His research interest is Flywheel Energy Storage System. He had been with the National Nuclear Energy Agency of Indonesia, from 1985-1994. Since 1994, he has been working as lecturer at Electrical Engineering Department of Mercu Buana University, Jakarta, Indonesia.
Kazuhiro Yamagata (Non-member) He was born in Tokyo,

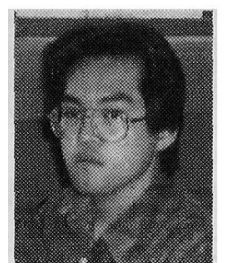
Japan in 1975. He received his B. S degree in Electrical Engineering from Tokyo Institute of Technology in 1998. In the same year, he has enrolled master program at Nuclear Engineering of Tokyo Institute of Technology, with research interest in Energy Storage System.

Jun Kobuchi (Member) He was born in Chiba prefecture,

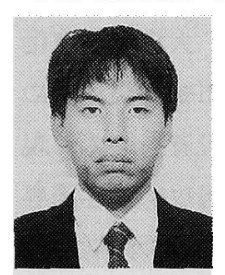
Japan, in 1973. He received his B. S, and M. S degrees from Tokyo Institute of Technology in 1996, and 1998 respectively. His reseach interests are Flwheel Energy Storage System and Electric Power System. Now, He has been joined Nippon Steel Company since April 1998.

Ryuichi Shimada (Member) He was born in Tokyo, Japan on

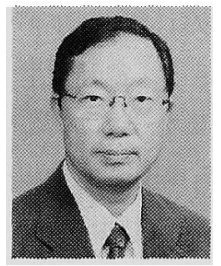
January 31, 1948. He received Doctor degree from Tokyo Institute of Technology in Electrical Engineering in March 1975. In the same year, he joined Japan Atomic Energy Research Institute. He had been with Electrical Engineering of Tokyo Institute of Technology as an associate professor from 1988 to May 1990 , and in March 1990 he became a professor. Since May 1990, he has been with the Research Laboratory for Nuclear Reactors at same university. His research interests are High Current Technology, Large Power System and Fusion Plasma Control. 